\title{
Patient Education
}

National Cancer Institute

\section{Source}

National Cancer Institute. Patient Education. NCI Thesaurus. Code C16959.

The process of imparting information to a patient that will help them to maintain or improve their health. 